\title{
Innovative Learning in the Age of Industry Revolution 4.0
}

\author{
Shirley Gilbert \\ Western Sydney University, Australia \\ S.Gilbert@westernsydney.edu.au \\ Allan Leslie White \\ SEAQiM Indonesia
}

\begin{abstract}
In 2018 the Indonesian Ministry of Industry (KPRI) released a document 'Making Indonesia 4.0', in response to the Fourth Industrial Revolution (4IR), setting out the Indonesian aspirations, the five focus sectors, the ten national priorities, the economic benefits, the job creation, and the next steps to ensure Indonesia's future development. While all the ten priorities are important, of specific interest to education are: priority 5 that aims to advance network and digital platforms; e.g. $4 \mathrm{G}$ to $5 \mathrm{G}$, Fiber speed $1 \mathrm{Gbps}$, Data center and Cloud, and; priority 7, which aims to redesign the education curriculum and create a professional talent mobility program using a STEAM approach. A transformation of the schooling system is needed which is different to a reform as reform concentrates upon the existing structure and system whereas a transformation works to create different systems and structures. The basis for success lies in the hands of Indonesian teachers and lecturers. This paper will also discuss developments in brain research, and the teaching behaviours that are conducive to producing students with higher order and creative thinking skills and the ability to solve complex problems.
\end{abstract}

Keywords: Fourth industrial revolution, making Indonesia 4.0, STEM, STEAM, school teaching and learning, brain research, long term memory, short term memory, compression, crossdisciplinary, multidisciplinary, interdisciplinary, transdisciplinary integration.

\section{Introduction}

The World Economic Forum (WEF) and the Asian Development Bank (ADB) jointly produced a white paper that focused on the impact of the Fourth Industrial Revolution (4IR) on the Association of Southeast Asian Nations (ASEAN).

The Fourth Industrial Revolution refers to a set of highly disruptive technologies, such as artificial intelligence $(\mathrm{AI})$, robotics, blockchain and $3 \mathrm{D}$ printing that are transforming social, economic and political systems and putting huge pressure on leaders and policymakers to respond. (WEF \& ADB, 2017, p.4)

The white paper sets out some of the gains and losses as a result of the Fourth Industrial Revolution and provides a number of suggestions for the ASEAN body and the individual member countries to consider.

In 2018 the Indonesian Ministry of Industry (KPRI) released a document 'Making Indonesia 4.0' setting out the aspirations, the five focus sectors, the ten national priorities, economic benefits, job creation and next steps for future development. While all the ten priorities are important, of specific interest to education are: priority 5 that aims to advance network and digital platforms; e.g. 4G to 5G, Fiber speed 1Gbps, Data center and Cloud, and; priority 7 , which aims to redesign the education curriculum and create a professional talent mobility program. 
'Making Indonesia 4.0' listed the First Industrial Revolution as involving the introduction of mechanical production using steam and water at the end of the $18^{\text {th }}$ century. The Second Industrial Revolution involved the introduction of mass production based on the division of labour at the beginning of the $20^{\text {th }}$ century. The Third Industrial Revolution involved the introduction of electronics and information technology to further automate production at the start of the 1970s. And the Fourth Industrial Revolution involved the introduction of cyber physical systems happening now.

At the Education World Forum in London in January 2018, the Indonesian Minister for Research, Technology and Higher Education, HE Prof Mohamad Nasir, elaborated further upon Indonesia's intended response to the 4IR. Of specific interest to school mathematics was his discussion of disruptive technology in higher education institutions and planned solutions involving competency based education to cater for the needs of students, the internet of things bringing greater connectivity and communication, virtual or augmented reality providing avenues for greater accessibility, and artificial intelligence (AI) and big data. He pointed to the need to add new literacies to usual ones of reading, writing and mathematics. The new literacies would involve:

1. Data literation which is the ability to read, to analyze, to use information (Big Data) in the digital world;

2. Technology literation which is the ability to understand mechanical (system) work, to use the application of technology like (Coding, Artificial Intelligence, \& Engineering Principles); and,

3. Human Literation which is Humanities, Communication and Design.

These are of interest to schools as the schooling system is expected to provide the basic foundations and learning necessary to succeed at a university level.

From this brief introduction it is apparent that the Fourth Industrial Revolution will require a transformation of education. A transformation is different to a reform as reform concentrates upon the existing structures and systems whereas a transformation works to creating different systems and structures. The schooling and tertiary systems will be expected to deliver students who have the skills needed by 4IR, which include technical capabilities, creativity and innovative problem-solving. To produce students who expect to have several "careers" during their working lives rather than just one, and are motivated to participate in adult training and lifelong learning. Schools and tertiary institutions will be expected to embrace online education and access education across borders, credit transfer and professional networks.

One aspect that appears in the 4IR documents is the support for a STEAM curriculum integration which is the integration of the disciplines of Science, Technology, Engineering, Arts and Mathematics. This is an extension to the worldwide movement to STEM integration and will be briefly discussed in the next section. 


\section{A STEAMing Issue}

There appears almost universal agreement that in an unknown future world, those countries that have a strong science, technology, engineering and mathematics (STEM) workforce and industry will be those countries that prosper in the future. It is a recognition that STEM skills, knowledge and values form the basis for future innovation and development. Increasing demand by business for creativity and higher order thinking skills, and greater economic competitiveness among countries, has influenced governments and educators to promote the need for greater attention across all levels of schooling and tertiary institutions towards STEM disciplines. However there has been a reaction to this narrowing of the curriculum and STEAM arises from those arguing for a broader vision.

It is claimed that STEAM education engages students with five interconnected ways of knowing: cultural self knowing, relational knowing, critical knowing, visionary and ethical knowing, and knowing in action (Taylor, 2015), and involves teachers developing a humanistic vision of $21^{\text {st }}$ century education and their role as professionals.

So, what does STEM or STEAM integration mean? Any cursory reading of the literature will reveal a range of terms used for STEM integration such as a multidisciplinary approach, a transdisciplinary approach, an interdisciplinary approach, or a crossdisciplinary approach. While these approaches share some similarities and are related, they are not interchangeable, and they manifest themselves in many different activities. They are complementary rather than being mutually exclusive. The problem for any reader is that the terms are often used incorrectly, loosely and/or interchangeably. So, the reader needs to ignore what the authors are calling their approach and try and determine which term is correct for the approach described. For most approaches, the term multidisciplinary applies.

In order to try and clarify these approaches, Figure 1 that follows places the approaches on a scale of integration.

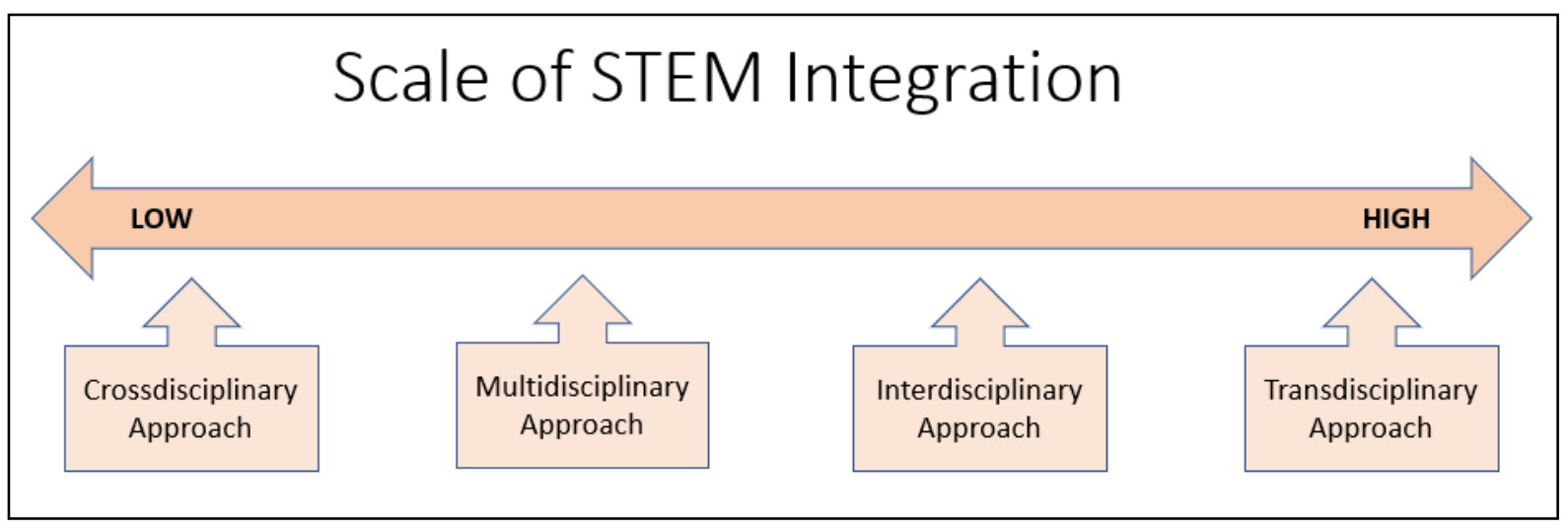

Figure 1. The scale of integration of disciplines for STEM approaches.

A Crossdisciplinary (or disciplinary approach) is where a teacher views one STEM discipline from the perspective of another. It could involve a mathematics teacher looking at the engineering syllabus and choosing something from that syllabus to integrate with the 
mathematics content. Or a science teacher reviewing the mathematics curriculum and integrating some mathematics content into the science program. Essentially the teachers remains within their subject or discipline and the discipline boundaries remain intact.

A multidisciplinary approach is where teachers from different STEM disciplines work together, each drawing on their STEM disciplinary knowledge. Usually for schools, mathematics teachers will still teach their mathematics program but will include where possible links to other STEM disciplines by working with teachers from those disciplines, often using common tasks that have been designed by those teachers. In terms of a scale of integration multidisciplinary approaches are less integrated compared to the interdisciplinary or transdisciplinary approaches as they maintain current teaching disciplines but multidisciplinary approaches are greater than crossdisciplinary approaches because multidisciplinary approaches use material that intersects with other disciplines. Multidisciplinary approaches may take the form of a school-based program adopting a thematic approach whereby a common theme is chosen and the teachers remain in their disciplines and teach the content and processes that are relevant to their discipline. Each theme may be presented in the form of an extended investigation. Where teachers from two or more of the STEM subjects design and teach integrated tasks, it places a considerable administrative load upon these teachers as they try to cover their current discipline mandated content requirements.

An Interdisciplinary approach integrates knowledge and methods from different STEM disciplines, using a real synthesis of approaches. Clarke (2014) recommends the construction of STEM education around practices which could include discourse, artefacts, reasoning and evidence and that teachers need training in horizontal expertise where they boundary cross by stepping into unfamiliar domains. Multidisciplinary approaches often merely juxtapose different disciplinary contributions whereas interdisciplinary approaches are better coordinated and integrated. An interdisciplinary approach may take the form of a teacher following a new curriculum that has been designed and distributed by the education authorities to include an interdisciplinary approach. So, a mathematics teacher would then teach a common program that is highly integrated with the other STEM disciplines for a majority of classroom time, and only teach mathematics on its own for a small percentage of classroom time. This places a burden upon the education authorities to provide a transformative curriculum. As stated earlier, a transformation is different to a reform as reform concentrates upon the existing structures and systems (such as multidisciplinary and cross disciplinary approaches) whereas a transformation works to create different systems and structures.

A transdisciplinary approach to STEM curriculum integration dissolves the boundaries between the conventional disciplines and organizes teaching and learning around the construction of meaning in the context of real-world problems or themes. A school transdisciplinary approach to STEM may adopt a curriculum based upon a newly designed and distributed curriculum from the education authorities where the teacher follows the program that integrates the content and strategies of all disciplines. The type of teacher required for this option requires an expertise in all four STEM disciplines or at least three. 
Training teachers with expertise in all four disciplines or at least three requires specialist training and selection of teachers who will be able to fulfil the curriculum needs and pedagogical challenges. Apart from the increased cost of inservice or preservice education, people meeting the initial requirements will be competed for and sought by the business world for exactly the same skills and learning that qualifies them for teaching this form of STEM integration.

So to conclude this section, the 4IR documents provides many challenges and the responses will be complex and involve multiple variables and it is beyond the scope of this paper to consider all aspects. Rather the rest of this paper will concentrate upon the schooling system and specifically upon the teaching and learning process. The aim of the teaching process is for long term memory retention in the brain of the students. With developments in brain research, we have a clearer picture of what teaching behaviours are conducive to producing students with higher order and creative thinking skills and the ability to solve complex problems.

\section{Learning and Understanding}

The aim of teaching mathematics or any subject in schools is to help students store their mathematical knowledge and experiences in the long term memory of their brain. The brain has over 1 billion neurons and any neuron can communicate with up to 10,000 others. The neurons in the brain continually fire in parallel as the brain works through the huge input of information by simply discarding irrelevant data and focusing only on a few important aspects at any given time. This is called the immediate memory and it is where the brain stores information briefly until the learner's brain decides what to do with it. Information remains here for about 30 seconds after which it is discarded as unimportant. Sousa (2008) stated that scientists currently believe there are two types of temporary memory: the immediate memory and the working memory which is the place where the brain stores information for a limited time of 10 to 20 minutes usually but sometimes longer as it is being processed. The basis of whether new information is transferred from the immediate to the working memory relies on the brain deciding that the information is either relevant or meaningful. The rest are quickly forgotten and discarded.

To transfer from the working memory to the long term memory, the brain requires the new information to be both relevant and meaningful (makes sense). This transfer involves more brain processing which results in greater neural connections and the formation of networks that are integrated (connected knowledge).

So when a child learns a new concept, an electric signal sparks, cutting across synapses and connecting different parts of the brain and forms networks of neurons that fire together. If the child learns a concept deeply, then the synaptic activity creates lasting connections in the child's brain (long term memory), whereas surface learning quickly decays. Skipping the sense making step creates a fragile understanding and cognitively expensive memorization (fills the working memory). When someone only memorizes, every new fact is like an island which is more easily forgotten because it either stays in the working memory or remains unconnected knowledge in the long term memory. 
The more a child uses the networks the more developed they become until eventually they become automatic. Understanding patterns in mathematical facts compresses the cognitive load required to recall these related facts. Sense making promotes deep, robust and flexible understanding, allowing students to apply what they know to new problems. Thurston (1990) states the process of building understanding leads to insight. Insight was apparently derived from a Dutch word for 'seeing inside' and is loosely defined as the process within the mind of a learner who when exposed to new information enables the learner to grasp the core or essential features of a known problem or phenomena. An insight seems to result in a connective process within the brain or a quick restructuring that produces new understanding that is a compression of the connected information. Thus encouraging student insight is a goal in the process of teaching for understanding. Compression or automatic responses are not the result of rote learning. Rote learning relies only on memory whereas an automatic response is built upon compressed understanding in the brain. Most of my driving is automatic but is not based upon rote memory.

If certain networks are not used then they decay and eventually disappear. This key ability to grow and decay has been termed 'brain plasticity' or 'neuroplasticity'. Research has shown that the brain can reorganise itself in remarkable ways as a result of a change in stimuli. It is essentially a process of rewiring the brain by forming or strengthening new connections and allowing old connections to decay. The implications for education, and especially school mathematics teaching and learning are challenging. For example it overturns the traditional long held beliefs that some children are born with the ability to do mathematics, others are not.

Children are not always stuck with mental abilities they are born with; that the damaged brain can often reorganise itself so that when one part fails, another can often substitute; ... One of these scientists even showed that thinking, learning, and acting can turn our genes on and off, thus shaping our brain anatomy and our behaviour (Doidge, 2008, p. xv).

And that

... scientists now know that any brain differences present at birth are eclipsed by the learning experiences we have from birth onward (Boaler, 2016, p. 5).

Children are not born knowing mathematics or any other subject. They are born with the potential to learn. How this potential is nurtured, encouraged, and challenged is the responsibility of parents and teachers.

Why is meaning so important? Meaning or understanding determines the possibility that information will be learned and retained in the long term memory, the goal of all mathematics teaching and learning. Understanding, making sense or meaning is a crucial consideration of the learner's brain in moving information to both the working and long term memory.

Students may diligently follow the teacher's instructions to memorize facts or perform a sequence of tasks repeatedly, and may even get the correct answers. But if they have not found meaning by the end of the learning episode, there is little likelihood of long-term storage (Sousa, 2008, p. 56). 
Making sense, meaning or understanding does not have a single end point but refers to a process of an increasing accumulation of stimulation and connection.

Students can grasp high-level ideas, but they will not develop the brain connections that allow them to do so if they are given low-level work and negative messages about their own potential. (Boaler, 2015, p. xvii)

So drill and practice using only memorization is a poor strategy instead of the better strategy of drill and practice with understanding. Sousa (2008) contrasts two kinds of practices as rote and elaborative rehearsal depending upon their effects on the brain. Rote rehearsal is a process of learning information in a fixed way without meaning and is easily forgotten. Elaborative rehearsal encourages learners to form links between new and prior learning, to detect patterns and relationships and to construct meaning or connected knowledge. The construction of meaning involves the building of cognitive schemas that will assist long term memory. Elaborative rehearsal leads to meaningful, long-term learning. Of course there are a range of elaborative rehearsal teaching strategies that differ in success.

A consideration of the time allocated to practice or rehearsal reveals there is another distinction made in the literature between massed practice and distributed practice (Sousa, 2008). Cramming, which usually occurs in a brief intense time period just before an examination, is an example of massed practice where material is crammed into the working memory, but is quickly forgotten without further sustained practice. There is no sense making and so it never makes it into the long term memory. On the other hand, distributed practice is sustained practice over time, building understanding and resulting in long-term storage. Distributive practice resonates very strongly with the East Asian Repetitive Learning which is continuous practice with increasing variation as a route to understanding (Leung, 2014), and this is often misunderstood as a form of rote. Leung (2014) sought to clear up certain misconceptions around memorization with understanding and rote learning that are often used to criticise Asian countries.

\footnotetext{
Memorization may have a negative connotation for some Western educators, who see it as a sign of rote learning. But for East Asians, practice and memorization do not necessarily imply rote learning or rule out creativity. As Marton (1997) observed, in East Asia, "repetitive learning " is "continuous practice with increasing variation," and practice and repetition are considered a "route to understanding" (Hess and Azuma 1991). ... In East Asia, practice and memorization are considered legitimate (and probably effective) means for understanding and learning, and equating memorization without full understanding to rote learning may be too simplistic a view. (p. 600).
}

In Leung' statement, we can see that continuous practice with increasing variation is a way that the teacher builds understanding and procedural proficiency by providing challenges suited to the ability of the student. This leads to why challenge and struggle are so important to the brain.

\section{The Importance of Challenge and Struggle}

While many teachers try to make learning joyful and fun, brain research has shown that we should not remove struggle and challenge. Research shows that the brain improves and grows through concentration and challenge. When students struggle and make mistakes, synapses fire and the brain grows (Boaler, 2015). How can the brain keep growing in a fixed 
container such as the skull? The answer lies in the importance of sleep, as during sleep the brain 'takes out the rubbish' and reorganises itself to be more efficient. There are some researchers that see challenge as essential to the structure and nature of their discipline.

The focus on challenge is partly based on a perspective of the nature of mathematics. Mathematics is seen as a network of interconnected ideas. To build these networks of ideas it is necessary for students to process different concepts simultaneously, to compare and contrast concepts and to consider their application in different contexts. Connected to this is a perspective on how mathematics is learned. We consider that mathematics learning takes concentration and effort over an extended period of time to build the connections between topics, to understand the coherence of mathematical ideas, and to be able to transfer learning to practical contexts and new topics (Sullivan \& Davidson, 2014, pp. 605-6).

Why is allowing students to make mistakes important to brain growth, isn't the aim of teachers to stop students making errors? The answer to this question is yes and no, and lies with the teaching strategy of scaffolding. Scaffolding first introduced in the late 1950s by Jerome Bruner is the support given during the learning process which is tailored to the needs of the student with the intention of helping the student achieve certain learning goals. It aims to help the student to face and overcome challenges through struggle. So scaffolding allows students to make mistakes and to learn from their mistakes in order to overcome their challenges. Yet scaffolding also reduces mistakes as once the student is able to overcome the challenge then they will not make further mistakes. Brain research has revealed the importance of mistakes,

Educators have long known that students who experience 'cognitive conflict' learn deeply and that struggling with a new idea or concept is very productive for learning (Piaget, 1970). But recent research on the brain has produced what I believe to be a stunning new result. Moser and colleagues (2007) showed that when students make mistakes in mathematics, brain activity happens that does not happen when students get work correct. (Boaler, 2014, p.17)

So the brain thrives on challenge and struggle and to move learning into the long term memory requires both understanding and relevance. In the next section, a brief discussion of relevance will be presented.

\section{Attitudes and Beliefs about Learning}

An area of importance for students making a judgement of relevance is the area of attitudes and beliefs around learning and how the brain works. The school mathematics curriculum includes many facts, skills, procedures and concepts. Mathematics teachers are expected to teach the mathematics curriculum while inculcating positive attitudes towards mathematics and by engaging and motivating their students to work mathematically.

Psychologist Carol Dweck (2006) and her research team collected data over a number of years and concluded that everyone held a core belief about their learning and their brain.

Dweck categorised students' orientation to learning in terms of whether they hold either mastery goals or performance goals. Students with mastery goals seek to understand the content, and evaluate their success by whether they feel they can use and transfer their knowledge. They tend to have a resilient response to failure, they remain focused on mastering skills and knowledge even when challenged, they do not see failure as an indictment on themselves, and they believe that effort leads to success. Students with performance goals are interested predominantly in whether they can perform assigned tasks correctly, as defined by the endorsement of the teacher (Sullivan \& Davidson, 2014, p. 606). 
This led to a distinction between what they labelled as a fixed mindset and a growth mindset. Someone with a fixed mindset believes that while they can learn things, they cannot change their intelligence level. Whereas someone with a growth mindset believes that the brain can be changed through hard work and the more a person struggles the smarter they become. There is an obvious connection here between growth mindset and brain plasticity. Professor Jo Boaler (2016) in her book provides a wealth of research evidence involving mathematics learning that supports Dweck's work.

\footnotetext{
It turns out that even believing you are smart - one of the fixed mindset messages - is damaging, as students with this fixed mindset are less willing to try more challenging work or subjects because they are afraid of slipping up and no longer being seen as smart. Students with a growth mindset take on hard work, and they view mistakes as a challenge and motivation to do more (Boaler, 2016, p. 7)
}

So Brain research is saying that teachers when giving feedback to students should target the behaviour and not the child. "I am really proud of how hard you have worked" or "good thinking" are better than "clever girl" or "smart boy". It also applies to bad behaviour. Statements like "I am sad when you (bad behaviour) because I care about you and when you do this then others will think badly of you. I know you are better than that, so please stop ..." rather than saying "you are a bad boy".

\section{Conclusion}

If the Indonesian schooling system is going to meet the challenges of the Fourth Industrial Revolution (4IR) and to realise the goals of the government contained in the document 'Making Indonesia 4.0' then teachers need to be supported through education and training. This paper has sought to discuss some of the findings that brain research has provided to the teaching and learning process for all disciplines. It seeks to motivate teachers and lecturers to rethink their strategies so that they encourage students to accept challenge, to build their understanding, to develop links and connections within their knowledge, to develop positive attitudes towards their learning and knowledge.

The paper has also briefly highlighted the complexity faced by current teachers who are expected to remain at the forefront of change and deal with the consequences of this change, in particular take on the demands for a STEM approach without adequate training and support. The success of 4IR depends upon good teachers and lecturers. It is why all enthusiastic mathematics teachers are regarded as super heroes and foundation workers for the country (White, 2011).

\section{References}

Boaler, J. (2014). Unlocking children's mathematics potential: five research results to transform mathematics learning. Reflections, 39(2), 16-20.

Boaler, J. (2015: Revised edition). What's math got to do with it? How teachers and students can transform mathematics learning and inspire success. New York: Penguin Books.

Boaler, J. (2016). Mathematical Mindsets. San Francisco CA: Jossey-Bass. 
Clarke, D. (2014). Disciplinary inclusivity in educational research design: Permeability and affordances in STEM education. Keynote address presented at STEM Education and our Planet: Making Connections across Contexts. 12 July.

Doidge, N. (2008). The brain that changes itself: Stories of personal triumph from the frontiers of brain science (Revised Edition).Melbourne: Scribe Publications Pty Ltd.

Dweck, C.S. (2006) Mindset: the new psychology of success. New York: Ballantine Books.

Grey, E., \& Tall, D. (2007). Abstraction as a natural process of mental compression. Mathematics Education Research Journal, 19(2), 23-40.

Kementrian Perindustrian Republik Indonesia (KPRI) (Indonesian Ministry of Industry) (2018). Making Indonesia, 4.0. Jakarta: Author.

Leung, F. K. S. (2014). What can and should we learn from international studies of mathematics achievement? Mathematics Education Research Journal, 26(3), 579-605.

Nasir, M. (2018). Policy for Curriculum and Competencies in the 4th Industrial Revolution (4-IR). Paper presented at the Education World Forum 2018, London, United Kingdom, 22 January.

Sousa, D. A. (2008). How the brain learns mathematics. Thousand Oaks, CA: Corwin Press.

Sternberg, R. J., \& Davidson, J. E. (Eds.)(1995). The nature of insight. Cambridge, MA, US: The MIT Press.

Taylor, P. C. (2015). Transformative science education. In R. Gunstone (Ed.). Encyclopaedia of Science Education (pp. 1079-1082). Dordrecht, the Netherlands: Springer.

Thurston, W. (1990). Mathematical education. Notices of the American Mathematical Society, 37(7), 844-850.

White, A. L. (2011). School mathematics teachers are super heroes. Southeast Asian Mathematics Education Journal, 1(1), 3-17.

White, A. L. (2013). Mathematics education research food for thought with flavours from Asia. Southeast Asian Mathematics Education Journal, 3(1), 55-71.

White, A. L. (2014). Juggling Mathematical Understanding. Southeast Asian Mathematics Education Journal, 4(1), 57-67. ISSN 2089-4716.

World Economic Forum (WEF) and the Asian Development Bank (ADB). (2017), ASEAN 4.0: What does the Fourth Industrial Revolution mean for regional economic integration? Manila: ADB. 